\title{
Direct colonoscopic visualization of intrahepatic bile ducts in a post-pancreaticoduodenectomy patient
}

\author{
Tyler Aasen ${ }^{a}$, Yousef Usta ${ }^{a}$, Houry Achdjian ${ }^{a}$, Paul Berggreen ${ }^{b}$ \\ Phoenix VA Health Care System; Banner University Medical Center, Phoenix, Arizona, USA
}

A 79-year-old female was evaluated in consultation for painless jaundice. Past medical history was significant for obstructive jaundice secondary to distal bile duct stricture from a benign pancreatic head mass status postpancreaticoduodenectomy. She later developed recurrent cholangitis and during surgical exploration was found to have a left hepatic duct bifurcation stricture that was resected. Four years later the patient presented with fatigue, weight loss, and painless jaundice. Laboratory investigation showed elevated total bilirubin of $9.4 \mathrm{mg} / \mathrm{dL}$, alanine aminotransferase $645 \mathrm{IU} / \mathrm{L}$, aspartate aminotransferase $1088 \mathrm{IU} / \mathrm{L}$, and alkaline phosphatase $183 \mathrm{IU} / \mathrm{L}$. Endoscopic retrograde cholangiopancreatography (ERCP) was performed to evaluate for possible recurrent biliary stricture. A pediatric colonoscope was utilized to access the afferent jejunal limb with the hepaticojejunostomy. The afferent limb was intubated and the colonoscope was advanced freely with excellent visualization of the intrahepatic bile ducts at the anastomosis site (Fig. 1). The site of previous hepatic duct stricture was identified (Fig. 2) with no recurrence of stricture noted.

Assessment of biliary strictures remains difficult and direct visualization of bile ducts is traditionally obtainable through cumbersome flexible cholangioscopes or newer 'SpyGlass' (Boston Scientific, USA) cholangioscopy [1]. Bile duct visualization in post-surgical patients is less well characterized and there is limited evidence available regarding the role of ERCP in post-pancreaticoduodenectomy patients $[2,3]$.

Current indications for ERCP in post-Whipple patients include: evaluation of suspected biliary obstruction; recurrent pancreatitis; or persistent pain thought to be biliary or pancreatic in origin [3]. In post-pancreaticoduodenectomy patients, accessing the afferent limb to evaluate for bile duct abnormalities may be an underutilized endoscopic technique.

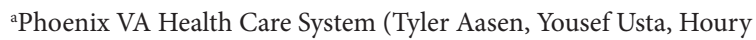

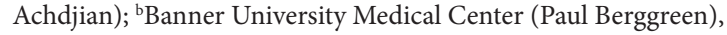
Phoenix, Arizona, USA

\section{Conflict of Interest: None}

Correspondence to: Tyler Aasen DO, 6735 W Harrison St, Chandler AZ 85226, Phoenix, Arizona, USA, Tel.: +1 7196710743 ,

Fax: +1 602839 4233, e-mail: tdaasen@gmail.com

Received 17 March 2016; accepted 26 March 2016; published online 7 April 2016

DOI: http://dx.doi.org/10.20524/aog.2016.0031

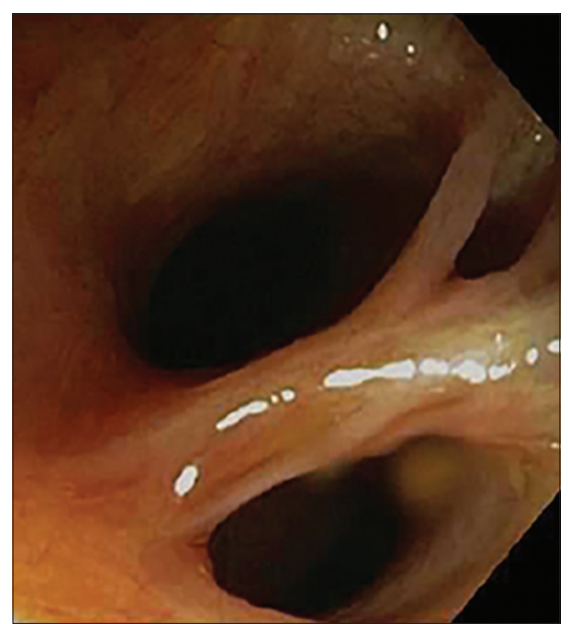

Figure 1 Visualization of intrahepatic bile ducts using a colonoscope after accessing the afferent jejunal limb with the hepaticojejunostomy

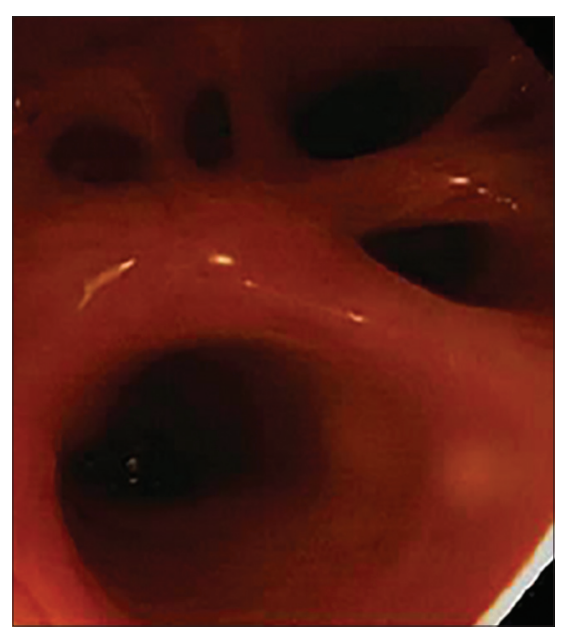

Figure 2 Evaluation of extensive network of intrahepatic bile ducts

\section{References}

1. AlAmeel T, Bain V, Sandha G. Clinical application of a single-operator direct visualization system improves the diagnostic and therapeutic yield of endoscopic retrograde cholangiopancreatography. Can J Gastroenterol Hepatol 2013;27:15-19.

2. Chahal P, Baron TH, Topazian MD, Petersen BT, Levy MJ, Gostout CJ. Endoscopic retrograde cholangiopancreatography in post-Whipple patients. Endoscopy 2006;38:1241-1245.

3. Farrell J, Carr-Locke D, Garrido T, Ruymann F, Shields S, Saltzman J. Endoscopic retrograde cholangiopancreatography after pancreaticoduodenectomy for benign and malignant disease: indications and technical outcomes. Endoscopy 2006;38:1246-1249. 